\title{
A construção de um modelo alimentar para a América Latina:
}

\author{
o ingresso da nutrição na agenda da saúde internacional \\ (1921-1949)
}

\section{Building a food model for Latin America:}

the entry of nutrition into the international health agenda (1921-1949)

\section{Érico Muniz ${ }^{1}$}

RESUMO: O contexto de reenquadramento das preocupações sociais do período entreguerras foi marcado pela criação de instituições e organismos internacionais para a tarefa de "racionalizar" os conhecimentos científicos sobre os alimentos. Sob a justificativa de que somente o crescimento econômico auxiliaria e incorporaria multidões na comunidade econômica global surgiam as primeiras políticas de assistência alimentar coordenadas pelos estados nacionais e pelos novos organismos internacionais como a Oficina Sanitária PanAmericana, a Organização de Saúde da Liga das Nações e o Instituto de Nutrição da América Central do Panamá. Neste artigo analisaremos os nexos presentes na ciência da nutrição em construção nessas políticas para a América Latina em interação com as tradições científicas sobre alimentação, sobretudo dos Estados Unidos e do Canadá, observando essas medidas embasadas em uma série de ações no campo da saúde internacional.

Palavras-chave: nutrição; saúde internacional; Organização de Saúde da Liga das Nações; Oficina Sanitária Pan-Americana; Instituto de Nutrição da América Central do Panamá.
ABSTRACT: The context of reframing the social concerns of the interwar period was marked by the creation of international institutions to "rationalize" scientific knowledge about food. Under the justification that only economic growth would help and incorporate people into the global economic community, the first food assistance policies coordinated by national states and new international institutions such as the Pan American Sanitary Bureau, The Health Organization of the League of Nations and The Institute of Nutrition of Central America of Panama. In this article we will analyze the links in the science of nutrition under construction in these policies for Latin America in interaction with the scientific traditions about food, mainly of the United States and Canada, observing these measures based on a series of actions in the field of international health.

Keywords: nutrition; international health; The League of Nations Health Organization; Pan American Sanitary Bureau; The Institute of Nutrition of Central America of Panama.

\footnotetext{
1. Doutor em História das Ciências pela Casa de Oswaldo Cruz/Fundação Oswaldo Cruz. Atualmente é professor adjunto da Faculdade de História e do Programa de Pós-Graduação em Linguagens e Saberes na Amazônia do Campus Universitário de Bragança da Universidade Federal do Pará (UFPA). Dedica-se a pesquisas sobre história das ciências e história da alimentação e do abastecimento. Contato: ericomuniz@ufpa.br.
} 
O movimento de ingresso da alimentação nos debates sobre a saúde internacional ocorreu paralelamente à crescente industrialização, com seus altos índices de desemprego, alcoolismo, violência, migrações para as cidades e crises de abastecimento de alimentos em várias partes do mundo no início do século XX. Nesse contexto, uma geração de médicos nutrólogos e especialistas na química dos alimentos passou a associar fome à mendicância e a outras mazelas sociais, o que possibilitava o encaminhamento de novas políticas sociais. A primazia do desenvolvimento como solução dos problemas econômicos e sociais em escala internacional adquiria força à época (Staples, 2006). Dessa maneira, a história da assistência social promovida pelos Estados nacionais e pela Liga das Nações a partir de 1919 pode ser entendida também como parte de uma fase de institucionalização científica e política da nutrição, momento de definição de parâmetros de uma ciência e de uma ação social.

Estudar as mudanças nos padrões alimentares das populações ao longo do tempo é uma das maneiras de fazermos a análise dos avanços (e recuos) da intervenção do Estado e das ciências no processo de definição de padrões alimentares cientificamente aceitos e referendados. $O$ poder de barganha dos médicos nutrólogos por investimentos em pesquisa foi aumentado em função de a alimentação ter se tornado alvo das preocupações e tensões populares não só na Europa, mas também em variados outros contextos urbanos. O processo de normatização dos conhecimentos científicos, a entrada das políticas de alimentação na pauta governamental e o protagonismo de determinados movimentos sociais e políticos foram determinantes para a criação de uma rede de assistência iniciada por restaurantes populares ou refeições escolares em diversos países. Na Europa dos anos 1930 e 1940 os saberes da ciência da nutrição associados às diretrizes para as políticas públicas tornaram-se centrais também para o desafio da reconstrução social, especialmente durante e após a carestia da Segunda Guerra Mundial (Vernon, 2007, p. 134).

A valorização da alimentação como fator responsável por elevar os padrões de vida das populações e como método preventivo de doenças ganhava força durante o surgimento das agências internacionais, sobretudo após 1921 com a criação da Organização de Saúde da Liga das Nações (OSLN). Anos mais tarde, os trabalhos para a definição de padrões de nutrição e pobreza marcariam a saúde internacional com ainda mais força após a crise de 1929 (Barros; Tartaglia, 2003). A Liga das Nações (1919-1946), que pouco produziu efetivamente do ponto de vista de políticas públicas em seus estados-membros, teve um destacado papel nas discussões sobre padrões de vida globais.

Com destaque ao protagonismo dos médicos nutrólogos, medidas e programas globais de assistência técnica foram lançados com fins de minimizar o problema da fome global ou ao menos a ameaça causada por ela. Ainda que o sucesso de algumas dessas medidas tenha sido extremamente limitado, especialmente no imediato pós-guerra, a ênfase em auxílio a programas para suplementação alimentar coordenados em escala nacional em detrimento dos ambiciosos planos de erradicação global de doenças representam a entrada definitiva da alimentação na pauta dos principais organismos internacionais (Ruxin, 1996).

Neste artigo discutiremos aspectos da gênese dos saberes em alimentação no continente americano a partir das contribuições das recém-criadas instituições internacionais nas décadas 
de 1920, 1930 e 1940. Veremos como as possibilidades da época produziram um novo momento nos determinantes do adoecimento e da saúde e como os estudos de uma geração de cientistas puderam fundar escolas, comunidades científicas e instituições públicas para viabilizar projetos de intervenção alimentar, processo que ocorreu simultaneamente ao movimento de modernização e urbanização dos países da Europa e das Américas. Observaremos a ciência da nutrição em construção, conforme sugestão conceitual de Bruno Latour (1999), que sinalizava para diferentes debates acadêmicos ao mesmo tempo em que recebia cobranças de ações práticas por parte dos estados nacionais.

\section{O internacionalismo e os debates na Liga das Nações}

O período de crise internacional entre 1919 e 1939 foi marcado por tensões sociais, econômicas e instabilidade política. Na Europa entreguerras, um novo concerto das nações se esboçava em meio ao crescimento de regimes totalitários. Esse contexto de abalo social colaborou para o desenvolvimento de ações com fins de intervir na alimentação das populações, incentivando debates que se deram nas instituições internacionais que eram criadas à época. Para Barona (2008), trata-se de um momento em que novas possibilidades de ação social traziam a nutrição para o dia a dia da cultura de uma sociedade e para a economia, com reflexos nos serviços de saúde pública. É nesse período que surgem a Liga das Nações e a Organização Internacional do Trabalho (OIT), em 1919. Assim como o Instituto Internacional de Agricultura (IIA), criado em 1905, essas instituições internacionais contribuíram para a inclusão das preocupações com alimentação na agenda estatal, especialmente após a crise de 1929. Essas agências trabalharam principalmente na elaboração das diretrizes de ação científica da nutrição, na busca de dietas balanceadas e na definição de padrões e paradigmas para o campo.

A primeira fase das ações da cooperação internacional em saúde que vai de 1851 a 1912 foi marcada por medidas que estiveram restritas à ameaça à circulação de pessoas e à implantação de cordões sanitários. A realização de encontros intergovernamentais esporádicos - foram apenas onze entre 1851 e 1913 - foi pautada por debates e conferências sanitários que contribuiriam para a aproximação entre política sanitária e ciência, debatendo a influência de doenças como a cólera, a febre amarela e a peste bubônica na agenda internacional, delimitando quando deveriam acontecer as quarentenas e isolamentos de doentes, sobretudo nas regiões portuárias (Howard-Jones, 1975).

A segunda fase da cooperação internacional em saúde corresponde ao momento em que os encontros das nações se institucionalizavam. A Oficina Sanitária Pan-Americana, atualmente Organização Pan-Americana da Saúde (OPAS), foi criada em 1902, firmando-se como primeira organização intergovernamental para debater saúde pública no novo momento da expansão do capitalismo industrial vivido após intensificação dos mercados na segunda metade do século XIX. Ainda mantendo o foco nas epidemias e no combate às endemias e aplicando medidas de vigilância sanitária, a Oficina foi uma das principais organizações com esse perfil. Cinco anos depois, em 1907, foi a vez da criação em Paris do Office International d'Hygiène Publique, com a função de realizar 
inventários sobre a situação das doenças; pretensões de lançamento de uma agência de saúde internacional na Europa (Howard-Jones, 1975).

Somente com a criação da OSLN, em1921, que uma organização de saúde internacional passou a contribuir para a formação de uma nova ordem política mundial de maneira mais significativa. Novas concepções de saúde e bem-estar social ganharam função pacificadora agindo na contenção de conflitos internos e guerras internacionais. Assim, ganhava força a visão de que o controle da circulação de epidemias não era suficiente para a saúde internacional; faziam-se necessários novos sistemas sociais com maior destaque para a formação de especialistas, sanitaristas e cientistas de laboratório, entre eles os médicos nutrólogos (Weindling, 1995). Dessa forma, a ação da OSLN culminou na entrada das ideias sobre nutrição nas concepções de cidadania como direito básico.

A busca por padronizar internacionalmente conhecimentos científicos incentivando pesquisas e definindo gradativamente parâmetros biológicos de especialidades médicas marcou a ação da OSLN (Borowy, 2009). Em 1935 construiu-se um consenso para o campo da nutrição, quando foi assinado um tratado sobre os índices de proteínas, vitaminas, gorduras e calorias necessárias para uma dieta balanceada e definição da desnutrição. Em 1937, uma Comissão Mista para Nutrição, Saúde, Agricultura e Política Econômica consolidou o movimento de entrada da nutrição na área de saúde pública na OSLN (Andrade, 2012, p. 153).

A ideia de que a melhoria nos quadros de saúde devia-se prioritariamente às mudanças sociais e econômicas da modernidade, como a maior capacidade de fixação do homem no espaço e o aumento de produção agrícola regular, ganhou força, e essa realidade também orientou os trabalhos da OSLN. Dirigida pelo bacteriologista polonês Ludwik Rajchman entre 1921 e 1939, a organização por vezes teve dificuldade de consensos dada a complexidade da nutrição como ciência em construção que combinava saberes da química, da clínica médica e de ordem cultural e econômica, o que dificultava a definição de quais intervenções deveriam ser administradas.

No entanto, essas ações produziram ganhos limitados quanto à implementação de projetos, à fundação de centros de pesquisa e ao estabelecimento de consensos científicos (Garcia, 2014). A OSLN inaugurou junto às crises do entreguerras um movimento inédito de padronização como maneira de alcançar a "objetividade científica", na prática e no discurso (Rodríguez-Ocanã; Zylberman, 2008). Entre 1934 e 1937, a formação de subcomitês na Liga das Nações, a realização de encontros de especialistas com levantamento de dados estatísticos e assinatura de novos acordos internacionais pavimentaram o caminho para a ação pública dos Estados nacionais na área de saúde. Como consequência, novas profissões em saúde emergiram na maioria dos países europeus.

O movimento de padronização das novas ciências ocorre, sobretudo, por dentro de agências internacionais, sendo a Liga das Nações o principal palco desse debate, ao mesmo tempo político e científico. Alguns dos desdobramentos dos estudose discussões travados na OSLN seriam debatidos, entre maio e junho de 1943, na Conferência da Organização das Nações Unidas para Alimentação e Agricultura (FAO) ocorrida na cidade de Hot Springs, na Virginia. Esse encontro relacionou os níveis de consumo de alimentos com a prevalência da desnutrição como uma questão a ser resolvida pela política econômica, pela agricultura e pela administração em saúde das nações presentes. 
O primeiro diretor da FAO, o médico escocês John Boyd Orr, especialista em nutrição da OSLN, associava depressão econômica, produção agrícola insuficiente e subnutrição urbana na mesma chave explicativa'. Em uma outra instância, ao convocar a conferência de Hot Springs, o presidente Franklin Roosevelt definia a ação da política externa estadunidense a uma atualização dos parâmetros para a nutrição em escala internacional.

Esses caminhos da cooperação internacional e dos debates entre comunidades científicas evidenciam a formação de uma complexa rede de saberes e poderes em alimentação. As oscilações de posições políticas e ideológicas e o acirramento da Guerra Fria que se avizinhava concluíram o sentido utilitário conferido a algumas das políticas de alimentação em debate. O legado da saúde internacional para as intervenções em alimentação contou com maciço engajamento das comunidades científicas e a contribuição dos estados nacionais participando do chamado processo de "nascimento do desenvolvimento" (Staples, 2006). Essas discussões deram origem a diversas políticas de intervenção no continente americano coordenadas pelos estados nacionais e pelos organismos internacionais.

\section{Alimentação na proteção social híbrida da América do Norte}

Em paralelo ao processo de formação de instituições internacionais, a noção de que era necessário melhor nutrir os trabalhadores para aumento produtivo surge nos países europeus industrializados em fins do século XIX. À época, o acesso aos alimentos era limitado especialmente nos grandes centros urbanos, onde eram comuns dietas à base de um alimento específico e com diversos registros de fomes coletivas agravadas na Primeira Guerra Mundial. A ação da filantropia e de grupos religiosos marcou as primeiras décadas de intervenções via refeitórios comunais que foram criados inicialmente na França e na Inglaterra; o modelo francês da soupe populaire ganharia repercussão, e medidas semelhantes seriam organizadas pela sociedade civil e pelos Estados nacionais nas duas primeiras décadas do século XX também nos Estados Unidos, no Canadá e na América Latina (Hurbutise, 2000).

A filantropia por meio dos incentivos às pesquisas científicas no campo da agronomia, criação de escolas de nutrição e serviços de alimentação foi também responsável pelos avanços que ficaram conhecidos ao longo da história do desenvolvimento de medidas de coletivização do bemestar social. Não se pode, portanto, compreender a história das ideias sobre assistência alimentar mirando exclusivamente nas ações governamentais; é necessário interpretar uma proteção social híbrida público e privada para a análise do ingresso das ideias de nutrólogos na sociedade. Isso se dá especialmente no contexto interno dos Estados Unidos e em suas relações com o Canadá.

$\mathrm{Na}$ história das relações entre Estados Unidos e Canadá, a definição da Segunda Guerra Mundial selou a cooperação entre políticas de defesa e economia entre os dois países. O primeiro ministro canadense William Lyon Mackenzie King e o presidente dos Estados Unidos Franklin 
Roosevelt mostraram, sobretudo após encontros da Permanent Joint Board of Defence, criada em agosto de 1940, que a parceria ia além da questão territorial e da ameaça de ataques por parte das potências do Eixo (lensen, 2004).

No que diz respeito à política social e à entrada da alimentação dos povos na agenda pública, eram comuns consultas de industriários e também do empresariado aos serviços de nutrição e de saúde das províncias estadunidenses. Na visitação domiciliar preparando as mães, na escola nutrindo crianças, nas fábricas, presídios ou em exército, a técnica de alimentação científica se fazia presente no fim dos anos $1940^{2}$. Pedidos de pôsteres, informes sobre a existência de cantinas e solicitações de plantas para instalações de refeitórios eram solicitações recorrentes de indústrias e associações aos governos dos Estados Unidos e do Canadá.

Preocupações semelhantes vinham de autarquias públicas nacionais e da cooperação desses países com a América Latina. As cozinhas de penitenciárias e os refeitórios dos exércitos frequentemente solicitavam cardápios e obtinham como resposta complexos planos alimentares geralmente ricos em ovos, carne, batatas e cereais, pães e doces ${ }^{3}$. A importância de manter uma dieta com alimentos de baixo custo e o alto uso de al guns itens dos cardápios eram observados pelos chamados dietistas em visitas aos presídios, preservando os índices calóricos julgados necessários ${ }^{4}$. Os dados sobre consumo de ovos, aliás, são pouco precisos ao longo da história, dado o caráter doméstico que envolvia esse hábito alimentar. É justamente após a Segunda Guerra Mundial que se multiplicou a prática das granjas, fazendo com que o consumo de ovos de galinha se incorporasse às tradições alimentares de diversos países e às recomendações científicas para uma alimentação balanceada (Flandrin; Montanari, 1998).

O intercâmbio entre instituições públicas, universidades e centros de pesquisa também chama atenção e é comprovado pela circulação dos periódicos. O National Research Council, principal conselho de pesquisa dos Estados Unidos, financiava na década de 1940 variadas pesquisas em alimentação desenvolvidas no Food and Nutrition Board subordinado à Division of Biology and Agriculture. Em 1947, foram financiadas publicações variadas sobre doenças em industriários e sobre a importância da luz solar para operários em diversas localidades. O papel da alimentação junto à saúde dos operários ganhava ares de investimento econômico citado como "único caminho possível", pois garantiria aumento da produção e redução de faltas por motivo de doença 5 .

Para garantir um melhor rendimento de operários e soldados, técnicos em nutrição eram comumente chamados para dar respostas científicas à escassez de alimentos ${ }^{6}$. Os comitês

2 Letter from W. Burton Ayre to Dr. L. B. Pett (Chief in the Nutrition Division/Department of National Health and Welfare). Toronto. December 5, 1952. RG 29 vol. 967. Library and Archives Canada - Ottawa. (LAC).

3 Letter from L. B. Pett (Chief in the Nutrition Division/Department of National Health and Welfare) to G. L. Sauvant (Superintendent of Penitentiares). Ottawa. June 20, 1946. RG 29 vol. 967. LAC

4 Anna Y. Burns. Recommendations of Dietitian. May, 12, 1945. RG 29 vol. 967. LAC.

5 Letter to all members of the Committee on the Nutrition of industrial workers and sub-committees. Washington, DC. December 19. 1947. RG 29 Vol. 967. LAC.

6 Nutrólogos avaliavam as condições nutricionais de fábricas como boa, fraca ou pobre, trabalhadores de empresas de material bélico 
de nutrição comunitária, a participação da Cruz Vermelha na aplicação de questionários para projetos de alimentação escolar foram práticas recorrentes ao longo do ano de 1943 como parte das recomendações do Instituto Internacional de Agricultura da Liga das Nações. Entrevistas, exames médicos e dentários das crianças, testes bioquímicos de alimentos eram algumas das atividades administradas. A Cruz Vermelha, aliás, colaborou também na definição das quantidades mínimas semanais da alimentação adequada, ajudando a compor listas de alimentos básicos para a boa alimentação ${ }^{7}$.

As listas também eram utilizadas para o cálculo dos preços dos alimentos que eram definidos como básicos. Assim, leite, ovos, carnes, pães, frutas, vegetais, cereais e peixes tornavam-se as regras da alimentação balanceada ${ }^{8}$. A incorporação das gorduras nesses cálculos não surpreendeu costumes, dado que o consumo de gorduras animais e vegetais nos países industrializados havia sofrido grande aumento ao longo dos séculos XIX e XX. Na França, por exemplo, nota-se que o consumo de gorduras multiplicou-se em quase oito vezes entre os anos de 1781 e 1964 (Flandrin; Montanari, 1998).

Essa dieta também era considerada para medidas de auxílio financeiro para desempregados e famílias pobres, forte tradição na América do Norte desde 1929, quando os governos provinciais iniciaram programas ou campanhas para prover comida subsidiada em anos de crise. Esses auxílios consistiam em programas de bolsas para complementar o orçamento das famílias, devendo ser o valor gasto principalmente na compra de alimentos. Eram tempos da chamada "racionalização" dos conhecimentos sobre alimentos. A crescente participação de nutricionistas a partir da década de 1940 foi responsável pela incorporação das questões relacionadas à alimentação das famílias atendidas pelos programas de Cash Relief. A prática de auxílio financeiro destinado para compra de alimentos também ficou conhecida como food allowance e consistia em repasses mensais cotados pelos técnicos da área de bem-estar social buscando aproximar-se do auxílio mínimo segundo a comunidade de nutricionistas e gestores do programa ${ }^{9}$.

Apesar das queixas que davam conta do limite do poder de compra dessas bolsas, a vigilância sobre a finalidade que as famílias davam a esses recursos era intensa, chegando a ser mensal em alguns casos. Assim como observou Jaime Rodrigues em seu estudo sobre pesquisas de padrão de vida na cidade de São Paulo, em meio a esse tipo de fiscalização podem ter sido comuns recusas,

recebiam especial atenção com visitas técnicas, envio de recomendações e cardápios diários a um custo de US\$ 0,25 centavos. Cf. Letter from Aluminum Company of Canada to Miss Margaret Lock (Department of National Health and Welfare). Kingston, November 3, 1944. RG 29 vol. 978. LAC

7 Minimum adequate Weekly food lists. Letter from Helen C. Sackville and G. L Duggan to Lawrence Coke (Family Bureau). Ottawa. June 24, 1946. RC 29 vol. 929. LAC

$8 \quad$ Weekly Food list and cost for family of Five. Ottawa. May, 1946. RC 29. Vol. 942. LAC.

9 Letter to Alderman L. H. Saunders Chairman and Members of Committe on Public Welfare. Mar 5, 1943. 2 Fonds 0220 , Series 0100, File 00722. City of Toronto Archives (CTA). Os pedidos eram diversos, vinham de mulheres solteiras, idosos, famílias com muitos ou poucos filhos e, apesar das inúmeras solicitações, o valor do auxílio não era aumentado na maioria dos casos. Letter \# 2 to Alderman L. H. Saunders Chairman and Members of Committe on Public Welfare. Mar 5, 1943. 2 Fonds 0220, Series 0100, File 00722. CTA; Letter to The Comissioner. Jan 21, 1943. Cf. Letter to Alderman L. H. Saunders Chairman and Members of Committe on Public Welfare. Mar 5, 1943. 2 Fonds 0220, Series 0100, File o0722. CTA. 
esquecimentos e "erros" na cooperação com as pesquisas (Rodrigues, 2011). Apesar do caráter oficial das fontes consultadas, é possível em alguns casos imaginar as estratégias de resistência utilizadas junto aos assistentes sociais canadenses e americanos que visitavam periodicamente as famílias participantes de projetos para averiguar evidências de que o dinheiro havia sido usado apenas para compra de alimentos e não para outros fins, devendo qualquer irregularidade ser relatada ${ }^{10}$.

As visitas mesclavam o caráter fiscalizador com uma pretensão educativa. O foco de atuação eram as crianças que foram definidas como alvo de programas específicos, geralmente contando com materiais educativos ilustrados e com histórias em quadrinhos; sem muitos detalhes sobre como viabilizar a dieta ideal. A função da nutricionista em seu trabalho social era fundamentada em educar as populações pobres para os hábitos alimentares considerados saudáveis a despeito de problemas econômicos e irregularidades na distribuição de alimentos. Nota-se aqui a influência de ideias dos chamados estudos de comunidade. Essas pesquisas caracterizaram-se por uma derivação do método antropológico para estudo de "sociedades primitivas", posteriormente deslocado como referencial também para "sociedades complexas", e eram muito comuns no campo da saúde pública e das ciências sociais nos Estados Unidos desde os anos 1920 (Oliveira; Maio, 2011). Na atuação desse tipo de visitação domiciliar, os hábitos alimentares começavam em casa, e justamente lá deveriam ser modificados. Através dos periódicos de províncias e trabalhos em universidades, práticas como superação de tabus alimentares, substituição de alimentos usados em excesso e identificação das principais dificuldades eram debatidas pela comunidade de médicos e nutricionistas.

A interação entre universidades e burocracia estatal para gestão dos programas e campanhas de auxílio alimentar foi determinante na formação de pessoal e divulgação das ideias em nutrição nos anos 1940. Os periódicos sobre nutrição criados a partir da década de 1940 tiveram importante papel na ampla divulgação de ideias e conceitos em nível internacional. Assim, temas relacionados ao papel da alimentação na saúde pública, pesquisas de padrões alimentares e os problemas relacionados à desnutrição eram debatidos e comentados em meio à valorização das ações educativas como possibilidade de mudança de hábitos alimentares. Historicamente, os periódicos e o jornalismo médicos cumpriram uma função de legitimação social da ciência, além de serem responsáveis pela divulgação e por notabilizarem disputas científicas entre paradigmas de sociedades e academias médicas (Ferreira, 2004).

O próprio debate sobre o padrão nutricional calórico em detrimento do proteico não era um pleno consenso entre as comunidades científicas de nutricionistas da época. Os níveis calóricos historicamente haviam crescido amplamente e as diferenças dos níveis entre trabalhadores e a elite havia diminuído, sobretudo, nas nações europeias (Flandrin; Montanari, 1998). Na FAO, sob a gestão de Norris Dodd, tais informações de pesquisas laboratoriais compunham complexas estatísticas e debates científicos. Em 1949, em função de desdobramentos de debates internos, Dodd convocou uma reunião de um comitê de especialistas criado para debaterem os padrões calóricos humanos. $O$ brasileiro Josué de Castro compôs esse comitê, o que, de acordo com Maria Leticia Bizzo (2012), foi o 
ingresso definitivo de Castro na FAO, definindo a circulação dele em importantes esferas científicas e políticas de tomadas de decisão da agência. Norris Nodd assumiu a direção-geral da FAO entre os anos de 1948 e 1953. Norte-americano, Dodd já frequentava a agência e vinha da gestão de regulação do setor agrícola dos Estados Unidos (Bizzo, 2012, p. 117, 268).

\section{O papel dos Estados nacionais: assistência social e alimentação na América Latina}

As ações sociais na área da alimentação fizeram com que a distribuição gratuita ou subsidiada de refeições, sopas populares e alimentos para os mais pobres ganhasse força nos períodos de guerras. Os refeitórios populares seguiram cumprindo uma tarefa de minimizar o problema alimentar a que operários, desempregados e pessoas em situação de pobreza extrema estavam sujeitos especialmente após a crise de 1929. Uma série de programas foi criada, funcionando de maneira diferenciada conforme o contexto em que se organizavam em seus países. De caráter religioso, caritativo, público ou corporativo, podiam estar inicialmente mais ou menos associados a serviços de combate à pobreza, de recolocação profissional, assistência médica ou psicológica de seus usuários. Restaurantes, bancos de distribuição de alimentos e cupons para serem trocados por comida são exemplos de medidas que foram a base da construção do estado de bem-estar social de países da América Latina especialmente a partir da década de 1930 (Hurbutise, 2000).

Estudos recentes no âmbito de história da saúde pública e da alimentação têm focado nas relações entre assistência social e construção do Estado Nacional moderno na América Latina, com destaque para criação de restaurantes populares e refeitórios fabris. Por um lado, consideramos que a interação entre as políticas regionais, nacionais e internacionais de saúde e bem-estar na América Latina funcionaram como uma forma de regular os hábitos da vida cotidiana. Por outro, podemos identificar nas políticas nutricionais parte do processo de formação do Estado em tempos de desenvolvimento (Muniz, 2014).

Uma análise comparada sugere que podemos ainda observar a forma como o conhecimento científico é produzido em países em desenvolvimento. Em alguns casos, como no Uruguai, a assistência social para a alimentação surgiu atrelada à atenção materno-infantil. Em 1910, a assistência social uruguaia havia sido centralizada pela criação da agência Asistencia Pública Nacional, órgão conservador com ampla participação de mulheres católicas, liberais e feministas (Birn, 2006). Essa e outras agências do Uruguai na área de puericultura - com destacado perfil de caridade destinada aos pobres, mulheres e crianças - atingiram ampla cobertura na capital Montevidéu. Financiada em parte por doações privadas, a expansão da assistência social no Uruguai com a nacionalização das instituições de caridade consolidou-se nos anos 1920, quando a Asociación Uruguaya de Protección a La Infancia passou a se beneficiar também da cooperação internacional através da parceria com o movimento de caridade conhecido como "Save the Children", baseado em Cenebra. A nova agência uruguaia rapidamente organizou uma série de serviços para assistência alimentar, tais como merenda escolar e jantares em um refeitório na capital do país. 
Coordenado por médicos e com presença de mulheres da elite montevideana, os restaurantes populares chegaram a servir refeições para escolares no ano de 1930, configurando-se como uma experiência pioneira na América Latina (Birn, 2006).

No Peru, uma rede de restaurantes populares foi criada na década de 1930 como parte das ações na reconstrução do Estado nacional. Essa experiência foi parte da reorganização das forças políticas nacionais da esquerda, uma solução material e moral para as demandas urbanas dos tempos da Grande Depressão. Os refeitórios instalados na cidade de Lima, para além de alimentarem, tinham função de conter insurreições e protestos. Eram parte de uma experiência que dava resposta às greves e manifestações contra a escassez de alimentos. À medida que colocava em prática conceitos de higiene, organização e definição de padrões alimentares, esses refeitórios eram concebidos pelo governo também como uma "missão civilizatória" (Drinot, 2005).

No caso mexicano, protestos populares urbanos provocados pela vulnerabilidade, pelo pânico e pelo aumento do preço de alimentos básicos também foram problemas enfrentados, sobretudo, durante a Segunda Guerra Mundial (Ochoa, 2000). Em movimento semelhante ao realizado por outros estados nacionais, o governo organizou uma agência para gestão alimentar que passou a ser a principal unidade de serviço social do país. Os acordos firmados com os Estados Unidos em 1942 com ênfase nos processos de industrialização do país geraram forte crescimento urbano, especialmente na região da cidade do México. A partir de 1942 os meios de intervenção estatal na área de alimentação foram reconfigurados no governo do presidente Manuel Ávila Camacho. Na gestão de Ávila Camacho, marcada pela cidadania outorgada aos trabalhadores, uma rede de armazéns vendendo gêneros alimentícios subsidiados foi organizada a partir de 1943, inicialmente vendendo trigo, milho, arroz e feijões com subsídio estatal. Eram iniciativas temporárias no sentido de controlar o tamanho dos protestos e medir a demanda de alimentos que precisariam ser importados em tempos de crise sem alterações mais relevantes no modo de produção dos alimentos do país (Ochoa, 2000).

Situação semelhante era encontrada na Argentina, onde a política alimentar teve importante uso na propaganda governamental. O consumo de alimentos foi fundamental para a administração Peronista com extensivo uso dos programas de alimentação na propaganda oficial (Milanesio, 2010). Reunindo especialistas nacionais nos campos de nutrição, agricultura e saúde pública, o governo elaborou planos que articulavam o acesso à comida com a nova noção de justiça social implementada pelo governo de Juan Domingo Perón. Com metas alheias a alguns debates internacionais sobre nutrição como, por exemplo, a de que cada argentino deveria poder comer 150 quilos de carne por ano, as políticas de alimentação deixaram como legado um efetivo barateamento dos alimentos e uma tradição de subsídios governamentais aos itens da cesta básica (Milanesio, 2010).

No Brasil, em 1940, foi criado o Serviço de Alimentação da Previdência Social (SAPS). Essa agência firmou-se como a instituição nacional de política alimentar, administrando atividades de gestão de grandes refeitórios operários em condições higiênicas nos grandes centros urbanos. Além disso, foi também responsável por medidas educativas, projetos piloto de merenda escolar e de assistência em geral, consolidando-se como um marco para a ciência da nutrição e para a história 
das políticas de educação alimentar no país. A dinâmica de atuação do SAPS pode ser entendida como expansão de uma política de previdência social no contexto do governo Getúlio Vargas, ou seja, uma política social compensatória controlada pelo Estado (Muniz, 2014).

As experiências de casos nacionais latino-americanos e a decorrente formação de mão de obra especializada foram alguns dos fatores que viabilizaram a fundação do Instituto de Nutrição da América Central e do Panamá (INCAP), em 1949. Associado à emergência da reconstrução do pós-Segunda Guerra e do papel da nutrição nas agendas nacionais e nas agências internacionais, o INCAP tinha parte do seu financiamento oriundo dos governos nacionais da América Central e fundos OPAS voltados para a pesquisa científica e assessoria técnica a projetos de nutrição e saúde pública de seus países membros. Sediado na Guatemala e seguindo experiências prévias realizadas, sobretudo, no México, em Cuba e na Colômbia, entidades como a Fundação Rockefeller e a Fundação Kellogg desempenharam um papel central no financiamento de projetos dessa agência. Guatemala, El Salvador, Honduras, Nicarágua, Costa Rica e Panamá desenvolveram variadas pesquisas laboratoriais e administraram bolsas de estudos para enviarem pesquisadores para cursarem especialização em nutrição nos Estados Unidos (Scrimschaw, 2010). Enfatizando principalmente medidas de distribuição de gêneros alimentícios e a criação de campanhas no combate à desnutrição, o INCAP já representa um outro estágio da agenda pública para a nutrição, parte do desdobramento dos debates sobre direitos humanos adotados pela Organização das Nações Unidas (ONU) a partir de 1948.

Assim, o INCAP materializou a importância da alimentação para assistência social na América Latina. As ações públicas nacionais desenvolvidas na América Latina e no Caribe somadas às novas agências internacionais ganhariam força no fim dos anos 1940. Nesse momento de institucionalização da nutrição, os projetos de grandes refeitórios públicos e de venda de alimentos pagos pelo Estado cederam gradativamente lugar a projetos de intervenção química na composição dos alimentos com adição de vitaminas e minerais aos alimentos e fortificação de farinhas de trigo e de milho. Simultaneamente, medidas de ampliação do acesso à água potável, esgoto e iodetação do sal de cozinha eram implementadas em diversos países da região (Howard; Foster, 2004, p. 180).

\section{Considerações finais}

O advento do campo de saber da nutrição e a busca para solução dos problemas alimentares passaram a ser tecnicamente mensuráveis e possíveis de serem enfrentados especialmente a partir da criação das agências internacionais do entreguerras. A alimentação tornou-se fundamental nas agendas dos Estados nacionais, permitindo a criação de aparelhos de Estado para lidar com a ameaça trazida pelo inchaço urbano, por ondas de greves, protestos e desemprego. As tradições de nutrição forjadas no início do século passado viraram elementos importantes da saúde internacional (Weindling, 1995). 
Ainda que os ganhos materiais dos encontros da OSLN tenham sido limitados, foi no interior dessa agência, na década de 1930, que se processou uma significativa mudança de paradigma sobre saúde e adoecimento. A inclusão dos temas da habitação e da alimentação como determinantes da saúde e, portanto, alvos da ação dos Estados nacionais e da saúde internacional colaborou com a consolidação da nutrição como ciência aplicada capaz de dar respostas eficientes à fome e à desnutrição, realizando intervenção via saberes da química, de estudos sobre cultura e economia.

Esse novo estatuto social da ciência da nutrição permitiu que médicos nutrólogos fossem importantes partícipes da rede de assistência social construída no continente americano. Vimos em exemplos de projetos desenvolvidos no México, na Argentina, no Uruguai, no Peru e no Brasil que países da América Latina associaram as intervenções alimentares com o desenvolvimento urbano, sobretudo no período da Segunda Cuerra Mundial. Medidas de subsídios a gêneros alimentícios, projetos de merenda para estudantes e refeitórios urbanos para operários e desempregados marcaram a ação social desse período. Nos Estados Unidos e no Canadá sobressai a relevância social de nutricionistas que elaboravam planos alimentícios e cardápios para instituições públicas e privadas, além de terem mantido intenso trânsito de pesquisadores entre departamentos públicos de assistência social e intercâmbio entre universidades.

O protagonismo de determinados movimentos sociais - notadamente de trabalhadores urbanos-ésignificativo para entendermos a formação dessa nova assistência social no entreguerras. Na Europa da década de 1940, por exemplo, orientações nutricionais tornaram-se vitais ao desafio da reconstrução social, ainda durante a Segunda Guerra Mundial e nos anos seguintes (Vernon, 2007). Ao tentar elucidar o sentido atribuído a esse novo internacionalismo e o papel de nutricionistas e funcionários da cooperação internacional em saúde, temos um quadro complexo. Ao mesmo tempo em que temos um inegável fracasso dos esforços para reduzir a fome e a desnutrição no mundo, vemos uma geração de mulheres e homens de ciência comprometidos com a missão humanitária de redução das desigualdades. Médicos e técnicos identificados com o campo político da esquerda, simpatizantes da ideologia do desenvolvimento como forma de melhorar as condições de vida globais, solidariedade religiosa, idealismo humanitário, espírito de comunidade e a ação de entidades filantrópicas visitavam com intensidade o tema da desnutrição e da fome como mazelas que grassavam, sobretudo, no hemisfério sul nas décadas de 1930 e 1940.

A partir de 1945, vive-se outro momento de institucionalização da alimentação como problema social com a criação de agências especializadas, programas e fundos criados à época, especialmente a FAO, a Organização Mundial da Saúde (OMS) e o Fundo das Nações Unidas para a Infância (Unicef) e, em âmbito regional, o INCAP. Pesquisas, definições sobre os parâmetros nutricionais gerais da disciplina e programas globais foram lançados ao longo dos anos 1950 especialmente com fins de minimizar o problema da fome via assistência técnica a projetos específicos. Como desdobramento, ao longo dos anos 1950 a ênfase na nutrição social foi mais restrita à concepção de técnica capaz apenas de auxiliar programas para suplementação alimentar em escala nacional, diminuindo as expectativas e ambições em relação aos limites da cooperação internacional para alimentação das populações. 


\section{Referências}

ANDRADE, Rômulo de Paula. A Amazônia na era do desenvolvimento: saúde, alimentação e meio ambiente (1946-1966). Tese (Doutorado em História das Ciências e da Saúde) - Casa de Oswaldo Cruz/Fundação Oswaldo Cruz. Rio de Janeiro, 2012.

BARONA, Josep L. Nutrition and health. The international context during the inter-war crisis. Social History of Medicine, v. 21, n. 1, pp. 87-105, 2008.

BARROS, Maria Sylvia; TARTAGLIA, José Carlos. A política de alimentação e nutrição no Brasil: breve histórico, avaliação e perspectivas. Alimentos e Nutrição, Araraquara, v. 14, n. 1, pp. 109-121, 2003.

BIRN, Anne-Emanuelle. O nexo nacional-internacional na saúde pública: o Uruguai e a circulação das políticas e ideologias de saúde infantil, 1890-1940. História, Ciências, Saúde-Manguinhos, Rio de Janeiro, v. 13, n. 3, pp. 675-708, jul.-set. 2006.

BIZZO, Maria Letícia Galluzzi. Agências internacionais e agenda local: atores e ideias na interlocução entre nutrição e país (1932-1964). Tese (Doutorado em História das Ciências e da Saúde) Casa de Oswaldo Cruz/Fundação Oswaldo Cruz. Rio de Janeiro, 2012.

BOROWY, Iris. Coming to terms with world health: the League of Nations Health Organization, 19211946. Frankfurt: Peter Lang, 2009.

DRINOT, Paulo. Food, race, and working-class identity: restaurantes populares and populism in Peru. The Americas, v. 62, n. 2, pp. 245-270, out. 2005.

FERREIRA, Luiz Otávio. Negócio, política, ciência e vice-versa: uma história institucional do jornalismo médico brasileiro entre 1827 e 1843. História, Ciências, Saúde-Manguinhos, Rio de Janeiro, v. 11 (suplemento 1), pp. 93-107, 2004.

FLANDRIN, Jean Louis; MONTANARI, Massimo. História da alimentação. São Paulo: Estação Liberdade, 1998.

GARCIA, Monica. Mortality rates or sociomedical indicators? The work of the League of Nations on standardizing the effects of the Great Depression on health. Health Policy and Planning, v. 29, n. 1, pp. 1-11, jan. 2014.

HOWARD, Leathers; FOSTER, Phillips. The world food problem: tackling the causes of undernutrition in the Third World. Boulder: Lynne Rienner Publishers, 2004.

HOWARD-JONES, Norman. The scientific background of the International Sanitary Conferences, 18511938. Genebra: World Health Organization, 1975.

HURBITUSE, R. Aide alimentaire et pauvreté: vers de nouvelles formes de priorisation des clientèles et des interventions. In: LABERGE, D. (Dir.), L'errance urbaine. Sainte-Foy: Les Éditions MultiMondes, 2000; pp. 347-359.

JENSEN, Richard. Nationalism and civic duty in wartime: comparing world war in Canada and America. Canadian Issues, pp. 6-19, dez. 2004.

LATOUR, Bruno. Ciência em ação: como seguir cientistas e engenheiros sociedade afora. São Paulo: Editora Unesp, 1999.

MILANESIO, Natalia. Food Politics and Consumption in Peronist Argentina. Hispanic American 
Historical Review, v. 90, n. 1, pp. 75-108, fev. 2010.

MUNIZ, Érico Silva. Comida, trabalho e assistência social: a alimentação na agenda política brasileira (1939-1947). Tese (Doutorado em História das Ciências e da Saúde) - Casa de Oswaldo Cruz/ Fundação Oswaldo Cruz. Rio de Janeiro, 2014.

OCHOA, Enrique C. Feeding Mexico: the political uses of food since 1910. Wilmington: Scholarly Resources, 2000.

OLIVEIRA, Nemuel da Silva; MAIO, Marcos Chor. Estudos de comunidade e ciências sociais no Brasil. Sociedade e Estado, Brasília, v. 26, n. 3, pp. 521-550, set./dez. 2011.

RODRICUES, Jaime. Alimentação, vida material e privacidade: uma história social de trabal hadores em São Paulo nas décadas de 1920 a 1960. São Paulo: Alameda, 2011.

RODRÍGUEZ-OCAÑA, Esteban; ZYLBERMAN, Patrick. Improving public health amidst crises. Introduction. Dynamis, Granada, n. 28, pp. 19-27, 2008.

RUXIN, Joshua Nalibow. Hunger, science and politics: FAO, WHO and Unicef nutrition policies, 19451978. Tese (Doutorado) - University of London. London, 1996.

SCRIMSHAW, Nevin S. History and early development of INCAP. The Journal of Nutrition, v. 140, n. 2, pp. 394-6, fev. 2010.

STAPLES, Amy L. S. The birth of development: how the World Bank, Food and Agriculture Organization, and the World Health Organization changed the world, 1945-1965. Kent: Kent State University Press, 2006.

VERNON, James. Hunger: a modern history. Cambridge/Massachusetts/Londres: The Belknap Press of Harvard University Press, 2007.

WEINDLING, Paul. The role of international organizations in setting nutritional standards in the 1920 s and 1930s. In: KAAMMINGA, Harmke; CUNNINGHAM, Andrew (Eds.). The science and culture of nutrition, 1840-1940. Clio Medica, The Wellcome Institute Series in the History of Medicine. Amsterdã/Atlanta: Editions Rodopi B.V, 1995; pp. 319-332. 